\title{
Assessment of Technology-Enabled Learning Environment using UPSA Ghana as a Case Study
}

\author{
Prince Kelvin Owusu ${ }^{1} \&$ Matilda Poka Abazinge ${ }^{2}$

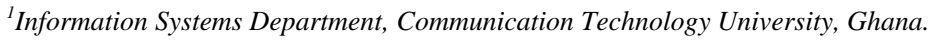 \\ ${ }^{2}$ Research Department, University of Professional Studies Accra, Ghana.
}

Copyright: @2021 Prince Kelvin Owusu \& Matilda Poka Abazinge. This is an open access article distributed under the terms of the Creative Commons Attribution License, which permits unrestricted use, distribution, and reproduction in any medium, provided the original author and source are credited.

This study aimed at assessing the technology-enabled learning environment at UPSA (University of Professional Studies, Accra) with the general objective of exploring the quality of teaching, learning, and management strategies that are important and needed in higher education in Ghana. The connected objectives answered were respectively to examine the status of Technology-Enabled Learning (TEL) environment, assessing the long-term policy and planning by management regarding TEL, evaluate the status of students' participation in TEL and to ascertain the challenges of TEL at UPSA. The study used a quantitative research method approach with two questionnaires designed with one for staff personnel and the other one for students in gathering data for this research. The study found out that regarding the TEL environment benefits, the status of TEL was not good enough since the university has not been able to provide the standard requirement such as an academic environment requires. The study also indicated that the university has not closely looked at the aspects of faculty governance that may inhibit or hinder the ability of academic leadership to foster and promote the mode of TEL. It was therefore concluded that UPSA does not develop mode of TEL environment in leveraging inter-studen communication. We recommended that UPSA should implement a pedagogical and instructional level knowledge and mostly in need of active, collaborative remote online laboratory instruction. We also recommended that UPSA should incorporate effective remote site facilitation to mimic the face-to-face interaction taking place in onsite laboratories and improve upon faculty governance to promote progress and intensifies academic leadership which will drive the changes effectively and incorporate effective remote facilitation for the promotion for online collaboration.

Keywords: Technology-enabled learning, Education, technology, The web, Teaching, Academic leadership, Online learning.

\section{Background of the Study}

The current century is characterized by a rapid pace of technological developments stimulated by innovations. These developments have impacted and paved the way for social transformation and emergent systems and structures at all levels of human activity, including student learning outcomes. It affects every facet of doing businesses and human endeavors and seeks to facilitate problems solving and/or finding solutions, enhance or facilitate learning strategies and to foster between various agencies in the development of skills through experiential and hands-on training that will result in better outcomes and success across the business environment. This new approach therefore sets goals and allows teams of students to experiment on how collaboration and communication tools are critical to maximize the value of strengths-based learning in social network.

Amy K. \& Andrea (2012) and Shawn, (2015), argued in support that to enhance education through technology, there is a need to focus more on the nature of social interactions that is fundamental and enabled through countless technological affordances. The emerging trend it may provide the impetus for many academic institutions across the world to assess the current state of higher education in a very deliberate manner to sustain and/or enhance the quality of student learning and experience. In support of the latter, Radmiller, (2016) studied the assessment of innovation and entrepreneurship (I\&E) with the view of enhancing students' learning outcomes in university education and identified links between formative assessment types and how it can enhance the learning of students. With that in mind, and related to the specific country Ghana, Kwame et al. (2013), were of the view that introducing the integration of ICT in Ghana tertiary Educational system has brought many challenges both for students as well as lecturers. 
In the last several centuries and more so the last few decades, traditional education relied on open courseware as fundamental in leading discussions and an adoption of open learning in educational institutions. After many iterations, it has led to the liberation of knowledge without shocking the designing, teaching and awarding processes (Anthony F. \& Anne-Christin 2013).

Lorayne et al., (2018) in a study conducted in Ontario, Canada, explored the issues related to quality teaching and learning through an assessment of higher education courses from the online teaching model. The results of their study concluded that online course and teaching may offer exclusive opportunities for both students and professors. Therefore, the benefits gained from digital technologies have increased the capacity and capability of higher education in designing quality learning environment and implementing quality assessment. However, implementing an online course does not guarantee a successful outcome but rather, the students will be able to understand key concepts more easily than in a face-to-face environment and therefore increase their opportunities to pursue, criticize, and hypothesize knowledge together in order to ensure a smooth transfer and acquisition of knowledges that can be applied directly to the business community (Lorayne et al., 2018). For effective success throughout the educational institutions across the country, the management of the universities should adequately provide the technology-enabled strategies and resources necessary to enhance educational delivery that will be attractive to all stakeholders and generate the appropriate support in the integration of ICT in teaching and adequately equip students to cope with ICT in learning process.

To begin with, there is a necessity for all to understand the place and role of technology-enabled learning in the university. In fact, it primarily helps to recognize and debate the impact of services and technology on educational institutions. Some key questions of the impact on institutions include how does technology help in the realization of learning outcomes or diminish this role and what is the impact of the social relations that emerge from it? Hence, it is necessary to have an effective and accurate technology-enabled learning strategy to be put in place to relate technology to the broader professional activities taking place in a university environment. In addition, it is necessary to closely engage with the risks of disruption on a global scale such as economic, environmental and socio-cultural risks. Specifically, any educational institution that embarks on it requires significant capital that impact the space for action and activity, climate change issues with the peak oil and energy prices and security that directly impact the use of technology and its resource management. Therefore, in an assessment of the technology-enabled learning environment, close attention should be paid to environmental consequences and effects on the use of technology.

As stated above, it has been observed that little research in Ghana has been conducted to dig deep into the assessment of technology enabled-learning environment in an academic institution and therefore, this provided a strong motive to the researcher to investigate and conduct this study at UPSA. Specifically, there has been no research conducted that effectively tackled the assessment of the quality of teaching, learning, and management strategies that are important and needed in higher education in Ghana. Consequently, this study will carefully evaluate the management practices and aptitude toward their readiness in a technology-enabled learning environment and explore the consideration of students' perspective when assessing technology-enabled learning 
because of the huge impact it has on students learning outcomes. (Hall 2011, Sivakumar \& Robertson 2014). The study therefore explores the quality of teaching, learning, and management strategies that are of importance and needed in higher education in Ghana through the assessment of the management in the use of the appropriate technology, process, and resources at UPSA.

\section{Literature Review}

In this era of rapid social transformation that is occurring along with the emerging systems and structures in this age of innovation, adequate learning strategies need to be vigorously put in place to foster collaboration, develop appropriate skills and competencies in order to enhance success across the business environment. This approach sets goals and allows teams of students to experiment on how collaboration and communication tools are critical in order to maximize the value of strengths-based learning in social network. Amy K. \& Andrea (2012) and Shawn (2015) reported that to enhance education through technology, there is the need to focus more on the nature of social interactions that is fundamental and enabled through the affordability of countless technologies. Consequently, for decades or even centuries, traditional education relied on open courseware as fundamental in leading discussions and an adoption of open learning in educational institutions. After many iterations, this has led to the liberation of knowledge without shocking the designing, teaching and awarding processes (Anthony F. \$ Anne-Christin 2013).

\section{A. Innovative Approaches Active Learning}

In a study of the preservice teachers at the University of West Bohemia, the Faculty of Education-Czech Republic, it was observed that using technologies-enabled learning, there was a significant improvement in both the content and use of teaching strategies in the preparation of students throughout their professional lives. In addition, based on the evaluation on how technology can be used, there were improvements in pedagogical innovative approaches or strategies for the design and implementation of technology-enhanced learning (Zbyněk \& Rohlíková 2018, 'Pedagogy and Technology-Enhanced Learning, in Matt Bower' 2017). They proposed a set of approaches as outlined below:

\section{(a) Action-Research}

One of the fundamental approaches used was based on action-research whereby all the people involved both students and staff were effectively monitored, and their evolution analyzed. Through this process, data were collected based on the feedback from both teachers as well as students and conclusions drawn (Zbyněk \& Rohlíková 2018, 'Pedagogy and Technology-Enhanced Learning, in Matt Bower’ 2017).

\section{B. Collaborative Learning}

The Collaborative learning approach refers to cooperation of a set of students towards the achievement of a set of goals agreed upon while assuring the production of high quality and competitive students. It therefore develops students' interest and self-confidence while improving their strategies in the elaboration of the assignments given to them. Throughout the process, they become more oriented to self-direction learning because they benefit immensely by in cooperating their life experiences which improves their effectiveness and ability to produce 
reliable data as well as becoming more research oriented. Thus, this strategy is particularly best suited in helping students to become more mature in decision making (Aderi et al. 2018, Martín-Gutiérrez et al. 2015)

\section{Problem-based learning}

This approach is widely adopted in various educational contexts for the promotion of critical thinking and problem-solving and it is appealing to many institutions to offer instructional framework in support of active and group learning.

It is a blend between collaborative and interdisciplinary learning since it contributes beyond the traditional clinical system and gives the opportunity to students to solve problems collaboratively while creating an effective mental model for collaborative learning, practices and reflections (Yew \& Goh 2016, Gorghiu et al. 2015).

\section{Inquiry-Based Learning}

Inquiry-based learning is an approach where students follow practices and/or protocols of professional scientists for conducting research and gaining knowledge and discovering new causal relations. It also provides ways to problem solving and an emphasis on active participation and learning responsibility with valuable opportunities available for students regarding their understanding of sciences. The implementation of this approach starts with the orientation stage, followed by conceptualization including many cycles and termination.

By investigation these phases for design-based purposes, the environmental theory works more effectively. The figure 1 below represents the appropriate flow in the Inquiry-based learning process (Pedaste et al. 2015, Edelson et al. 1999).

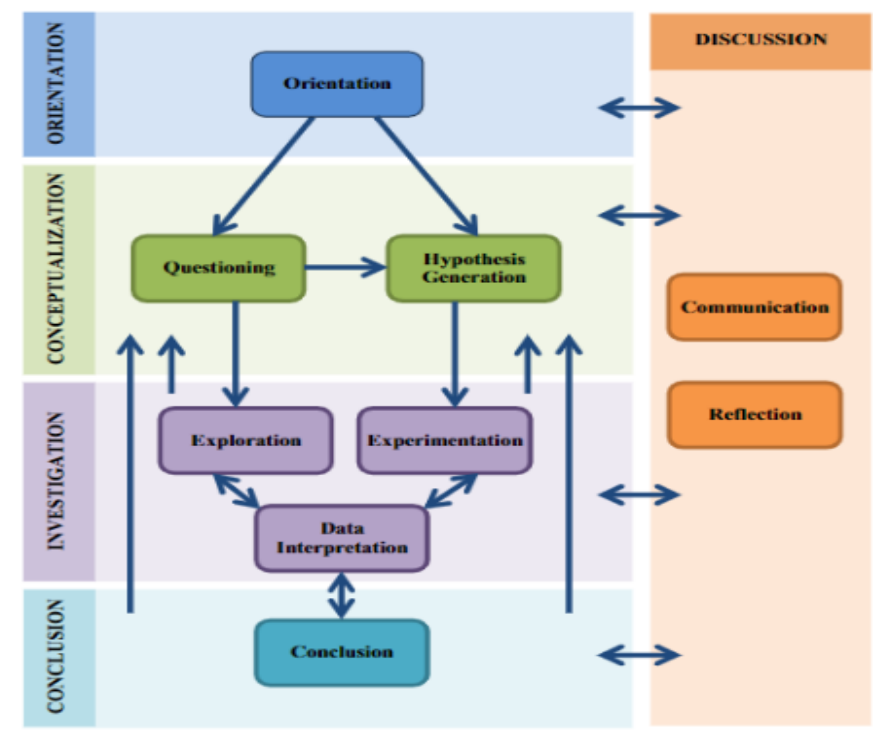

Figure 1: Inquiry-based learning Source: (Pedaste et al. 2015, Edelson et al. 1999)

\section{E. Digital storytelling}

The Conventional narratives or storytelling approach as technology enabled learning is recognized as enabler of larger emotional engagement in connection with the reader. It is also suitable to effectively address the difficulty of change in complex institutions such as a university (Quinsee \& Bullimore 2011, Robin 2016). 


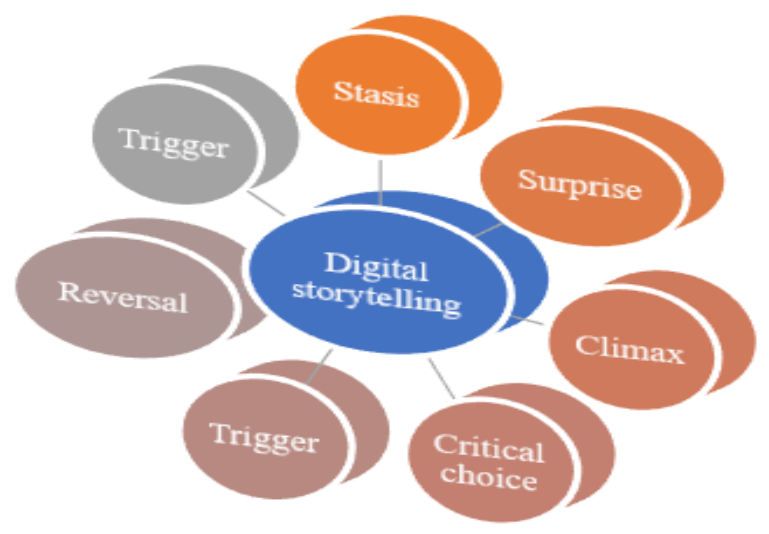

Figure 2: Digital storytelling Source: (Felix A. 2013, Quinsee \& Bullimore 2011, Robin 2016)

\section{F. Social networking learning}

Akers (2017) \& Emergingedtech (2019) associated social networking learning with behavioral learning theory that are widely accepted and applied to criminal and deviant habits. Nevertheless, these are misinterpretations of that theory. In support of this opinion, it is stipulated that it gives an in-depth knowledge and an authoritative discussion, concepts development, as well as empirical tests. In addition, it ensures and influences public policy that transforms the way things are done even in the academia and develop confidence among peers leading them to speak out and network with countless professionals of any field.

\section{(a) Goals}

The goals of Technology-Enabled Learning are to engage and empower learning through technology while scaling up personalized learning and blended learning as well as providing opportunities for practice and building projects for real audiences. In addition, it also cultivates and fosters connections between schools and community institutions while taking care of equity for learning through technology as well technology-based programs in order to boost student achievement Tech.ed (2019). Therefore, these goals have been outlined to reinforce technology-enabled learning as promoting authentic and meaningful learning. As stated, these goals have fundamentally specified the teacher's critical role in the application and/or the implementation of these strategies ('Pedagogy and Technology-Enhanced Learning, in Matt Bower’ 2017, Zbyněk \& Rohlíková 2018).

\section{G. Strategies for Technologies-Enabled Learning}

Coordinating an effective strategy that enables learning is very important because it is crucial in the process of reforming social relationships among individuals while respecting their key differences in adapting to a disruptive environment. In addition, an effective strategy is needed for the promotion of transparency, accountability and enables potential connectivity of people through co-operatives, resources, institutions and values for the sake of solving societal problems (Hall 2011, Lucas 2017).

\section{H. Humanizing the place of technology in $\mathrm{HE}$}

To make decisions for effective strategies, social relations between students and staff, institutional forms of production, exchange, and consumption of IT (information technology) need to be addressed. Therefore, it involves 
looking at technology-enable learning environment as a social medium used primarily to connect institutions to their staff and students allowing them to develop the critical ability to solve problems and continue learning. In addition, it also covers a process of reforming social relationship that is needed to analyze and evaluate the interaction between technology and human values.

\section{Benefit of Technology-Enabled Learning}

In the response to strategic changes, Sivakumar \& Robertson (2014) reported that Dalhousie University, Halifax, Canada had developed an interactive online platform within the university in order to deliver efficient remote learning experience to geographically remote master's students with the view of increasing its students through online education while maintaining the quality of teaching as the onsite programs. In view of this, the challenges were how to accommodate the technology enabled-learning environment that correlate with the pedagogical approaches and types of onsite interactions and learnings. In the modern world, to maintain the highly competitive standards of a university, there is a need to extend lifelong learning opportunities to students. This can be done through the use and the advancement of technology in network infrastructure and development of voice, multimedia protocols etc.

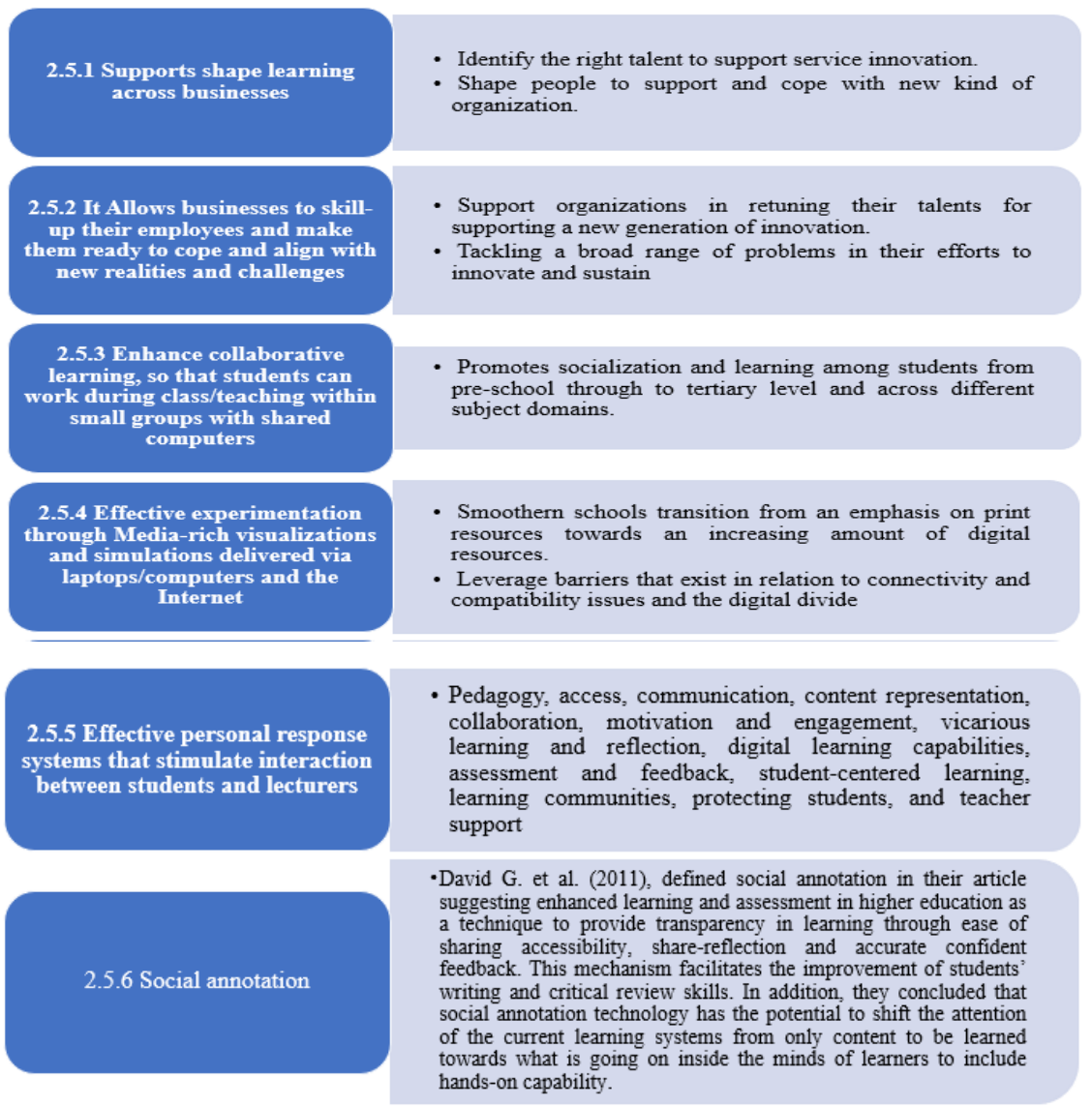

Figure 3. Benefits of Technology-Enabled Learning Source: (Demirkan \& Spohrer 2015, Novack, M. \& Goldin-Meadow 2015, Al \& Dunagan 2017, Gillies \& Gillies 2016, DIGGS 2014)

However, many challenges are encountered in the adoption and implementation of an effective technology-enabled learning environment that can ensure strong effective and secure student interaction that can replace effectively and 
efficiently the old face-to-face students' interactions. In addition, there are challenges in the support of respectable pedagogy and learning practices bearing in mind all the technical constraints regarding bandwidth, quality of service, real time student interaction, multiple user and security, effective online strategies that include suitable pedagogy, facilitation and skills building techniques in order to communicate knowledge and achieve the institutional goals and objectives ( Hall 2011, Sivakumar \& Robertson 2004). The benefits that technology-enabled learning offers are listed below (Elearning Industry 2019, yourtrainingedge 2019):

\section{J. Modes of technology-enabled learning}

There are three different modes of technology-enabled learning that correlate with the three well known pedagogical approaches and types of onsite interaction..

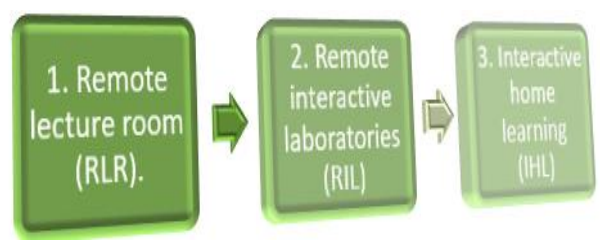

Figure 4: Three different modes of technology-enabled learning Source: (Sivakumar \& Robertson 2014, Hall 2011, Pechenkina \& Aeschliman 2017)

From the figure 4 above, the RLR is meant for emulating a classroom atmosphere and corresponds to the objectivist approach whereas the RIL, which corresponds to constructivist pedagogical approach is used to facilitate remote laboratory experience mentored by facilitators who uses collaborative methods to achieve learning outcomes. In addition, the third round corresponds to IHL that promotes inter-student communication while encouraging peer interaction and the uses of group processes in learning. To illustrate the mode of TEL, the Halifax site was used in order to both display the onside classroom along with the internet working equipment facility. An illustration has been given in Figure 5 below where the Halifax Internetworking lecture facility (HILF) is presented along with the remote site facilitation room (RSFR) which constitutes the RLR. In the other hand, the constitution of remote site through RIL is done with the Halifax Internetworking equipment facility (HIEF) (Sivakumar \& Robertson 2014, Hall 2011, Pechenkina \& Aeschliman 2017).

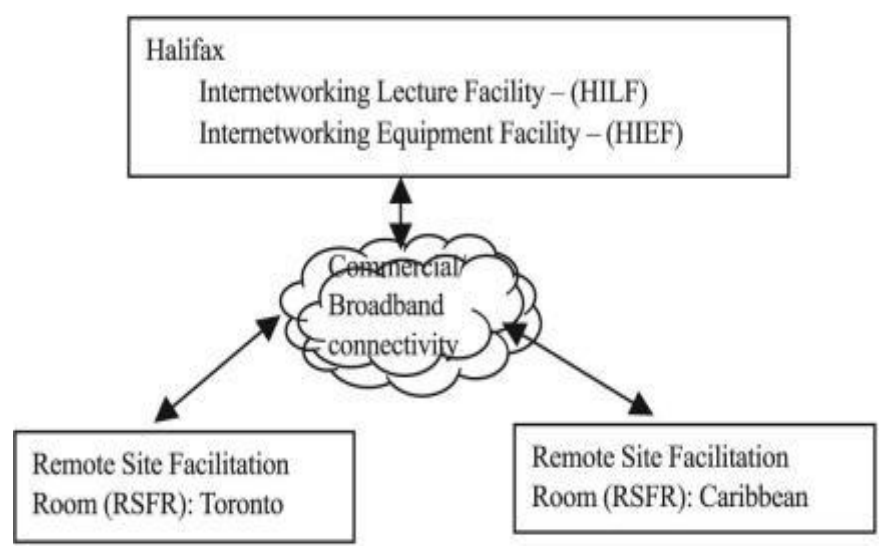

Figure 5: Modes of technology-enabled learning Source: (Sivakumar \& Robertson 2014, Hall 2011, Pechenkina \& Aeschliman 2017) 


\section{Theoretical Framework}

Peter \& Esther (2013) explained how the introduction of Information and Communication Technology (ICT) in teaching has provided graduates and lecturers the necessary skills to widely integrate ICT into their learning practices. One of the major difficulties in the implementation of a technology-enabled learning environment approach is going beyond the actual ways of doing things. For a sustainable educational business, an accurate approach that underlies institutional infrastructure and provides students with adequate mean to enhance their opportunities and experiences must be implemented. Therefore, stakeholders become autonomous and the outcome shared among everyone. The figure 6 from Price et al. (2016) is used as the Conceptual framework of the study while showing how the teaching and learning are influenced by technology in Higher Education and illustrates the complexity of the major factors that strongly influence the implementation of TEL and its management.

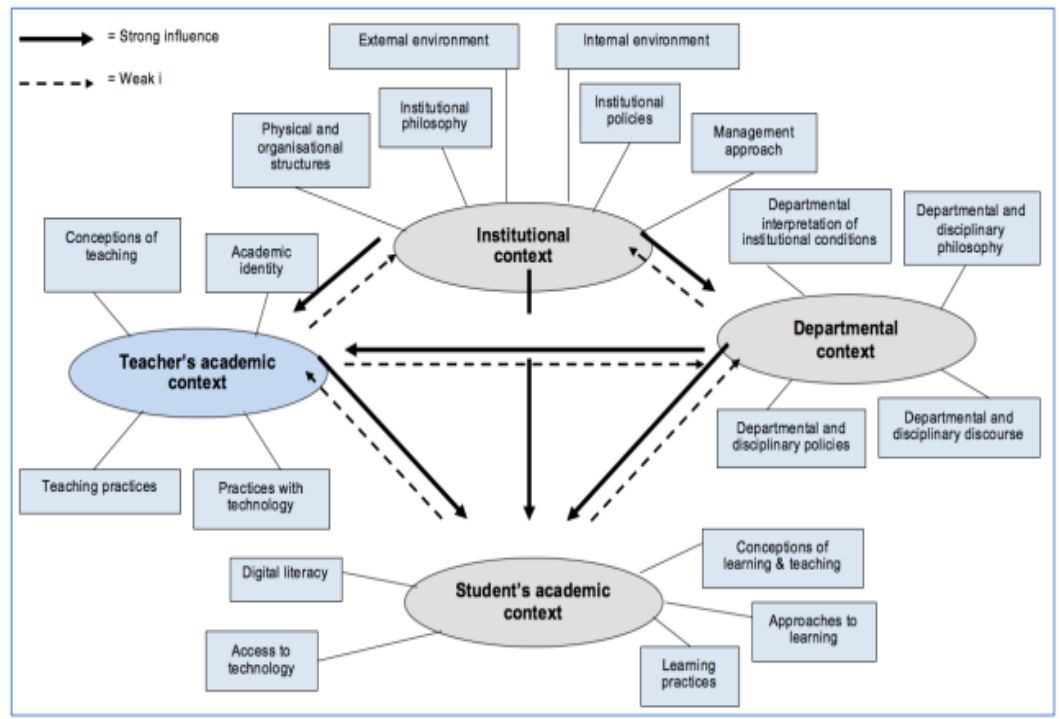

Figure 6: Theoretical framework

Source: (Price et al. 2016)

The influence of a university on its stakeholders can either enhance or derail its strategic initiative. For instance, if it has a negative influence on its students, the action to be taken is to leverage the staff and the approach used. The above framework presents the model of influence into four influential and interrelated factors to ensure an effective implementation of TEL through the teacher's academic context; the student's academic context; the departmental context and the institutional context.

\section{Methodology}

The research is focused on an in-depth investigation on issues related to the quality of teaching, learning, and management strategies in higher education in Ghana. We adopted a descriptive approach where data representing the reality on the ground were gathered and analyzed for interpretation and inferences. Through a quantitative approach, the study sought to develop a deeper understanding for the assessment of academic institutional management in the use of appropriate technology, processes, and resources. According to Fisher (2010) \& Saunders et al. (2009), a quantitative study helps the researcher with effective data collection using effective tools 
and is best suited when the researcher is having a greater number of subjects that makes it possible for generalization of the results with objectivity and accuracy. The research used a case study strategy for an effective assessment of the management practices and aptitudes toward readiness in a technology-enabled learning environment as well as an adequate design for enabling an assessment of complex decisions regarding the day-to-day activities' vis a vis of the use of technology. Therefore, the study focused on UPSA as a single case study and using questionnaire and secondary data obtained from various sources.

The population of the study consisted of Staffs and Students of UPSA. The staffs included Deans, Head of Departments, and Lecturers. The population of the students included those studying in Marketing, Accounting, and Information Technology Management of the university. The selection of the departments was made on the fact that they were the departments where technology infrastructure was made based on the fact in these departments, technology infrastructure was already deployed and implemented for at least a decade. The total possible population size of the study was five thousand three hundred and forty four $(5,344)$, corresponding to two hundred and seventy one (271) staff members, and five thousand and seventy three $(5,073)$ students according to (UPSA 2018). The appropriate sample size represents the number of participants a researcher selected in order to achieve effectively the research's objectives Fisher (2010), Saunders et al. (2009). In line with that, the sample size of three hundred and fifty-six (356) was selected that included core responsible educators and core practicing students focusing on alignment between learning goals, assessment forms and criteria and feedback. The distribution of the various research groups included forty-six (46) staff personnel which is made up of two (2) Deans, four (4) Head of Department, forty (40) lecturers. In addition, three hundred and ten (310) students were selected among the UPSA's student body made up of hundred (100) from Marketing, hundred and forty (140) from Accounting, and seventy (70) from Information Technology Management.

The sampling technique that was used was probability-sampling using simple random sampling where respondents were selected subjectively with equal chance in order to ensure transparency and accuracy (Fisher, 2010). The study was quantitative and thus the data collection methods were questionnaires coupled with some secondary data gathered from previous studies and UPSA's documents. Questionnaires were prepared and divided into two different types: the staff and student's questionnaire whereby each was designed in a user-friendly manner, close ended along with multi-choice questions and distributed to the targeted population. It was distributed during the lunch break time to increase the probability of participation by the respondents. Throughout the data collection process, the information was gathered from knowledgeable staff and trustworthy students from UPSA. For the questionnaire to be given, the student/staff was asked to present his/her student card/badge to prevent non UPSA's student /non UPSA's staff to participate in the survey and provide inaccurate responses. Thus collectively, the participants showed that they were highly competent in the answering of the questionnaire.

\subsection{Ethical Consideration}

Ethical consideration is an essential component when embarking on a research project because it requires the researcher to adhere to ethical norms and must have the strict commitment to protect the right of the participant while collecting data. As mandated by Coventry/GTUC university, each researcher was supposed to get ethical 
approval before the collection of the data Fisher, (2010) \& Saunders et al. (2009) Hence, it was imperative for the researcher to abide by all ethical guidelines and display ethical behavior throughout the research process and more importantly all the requirements of Coventry university related to intellectual property and plagiarism. In addition, the researcher strictly adhered to all UPSA policies and practices in place and complied with all the requirements of the university as well as collecting the data anonymously.

\section{Discussion of Findings}

Along with the overall objective stated at the beginning of the chapter and looking at the presentation, analyses made, below are the discussions relating to the findings.

The respondents of the students were mostly male with $51 \%$ for students and $60 \%$ for staffs' personnel even though the participation of female were also pertinent $49 \%$ for students and $40 \%$ for staffs. In addition, the staffs' personnel participation was mostly from both Information Technology and Management and Business Management department (22.5\%) and lecturers (47.5\%) were the most presents in the data collection. In the other hand, $92.1 \%$ of the students and $62.5 \%$ of staffs' personnel were holding master's degree in addition to only $66.7 \%$ of students who were UPSA's students for between 2 to 4 years. From the finding, it can be concluded that the respondents were knowledgeable enough in the responses given regarding the research's objectives.

\subsection{To examine the current status of technology-enabled learning environment at UPSA}

To perform that examination, the researcher looked at the benefit it may bring to the UPSA and the resources, services, and spaces UPSA has provided to ease the use and implementation of TEL. The analysis conveyed that most of students averagely qualified as acceptable (Mean 2.3766; SD of .9638) with all the statements regarding the benefit of TEL environment from TELENVPromSoscial to TELENVPromENB and similarly, staffs' personnel on their part also mostly agreed (Average Mean: 3.4925 round to 4) on these benefits.

This shows the contribution of TEL at UPSA from the perspective of the benefits it has brought to its students as well as staffs. In addition, the students gave their opinions on the Management ability to understand the Place of TEL in the University and the results indicated that it was acceptable as the average mean (2.45) showed along with the SD (1.007) and Variance (1.015). The results from both staffs' personnel and students are in-line that showed the status of the TEL from the perspective of the benefits. In the other side, regarding the resources/services and space provided, most staffs' personnel (average Mean: 1.8317 round to 2; average SD: 1.4865) supported that they were not available while likewise most students (average Mean: 1.8683 round to 2; average SD: .8392) argue the same way. It can therefore be concluded that the resources, services, spaces that UPSA provide to ensure a smooth implementation of TEL is not yet available giving therefore an effective status of the current TEL environment at UPSA.

To sum up, in view of the agreement in opinion regarding the benefits of TEL environment for both students and staffs' personnel, UPSA should therefore try to improve and sustain it to maintain it competitiveness as modern university because there is a need to extend lifelong learning opportunities for students as supported by (Demirkan and Spohrer (2015), M. \& Goldin-Meadow (2015), ELEARNING INDUSTRY and yourtrainingedge (2019)). 
5.2 To assess the long-term strategic policy and planning by management regarding technology enabled learning environment.

The analysis shows that most respondents (average Mean: 2.955 round to 3; average SD: 1.121) were neutral about the policy and its implementation. It also shows that most respondents (average Mean: 3.236 round to 3; average SD: 1.106) were neutral regarding the strategic plan for the implementation of TEL and similarly, most respondents (average Mean: 2.953 round to 3; average SD: 1.208) were neutral about technology strategy even though they were knowledgeable enough as having Information Technology \& management role. Moreover, most respondents (average Mean: 3.0166 round to 3; average SD: 1.0246) reported being neutral about the leadership for TEL even though most of them were having Business Administration as role.

Therefore, from this, the UPSA's management is not standing good in term of its policy and planning, leadership, and technology regarding the TEL. In line with this, Lucas (2017) recommended that faculty governance represents an important issue that inhibits progress and intensifies academic leadership, and that the entity should move ahead and take a step forward and acquires good leadership and faculty members which will drive the changes effectively.

\subsection{To evaluate the current status of students' participation in technology enabled learning environment}

The analysis indicated that most students (average Mean: 3; average SD: 1.2013; average Variance: 1.449) were neutral regarding UPSA TEL's strategy as the SD and Variance testify with small values not far from the mean. In the other hand, most students (average Mean: 2.402 round to 2; average SD: 1.16; average Variance: .8) have disagreed with the mode of TEL environment where UPSA should have had an RLR, RIR and IHL. In addition, they disagreed in their opinions for lecturers, the fact that UPSA provides access to broadband internet. The finding conveys that students do not have much information about TEL strategy which is helpful for student in their journey as explained by Lucas (2017). Similarly, it shows that the respondents disagree with mode of TEL environment at UPSA where UPSA emulate RLR, RIL and IHL, and other online benefits facilities. Moreover, as participation of students in the TEL environment, the study indicated that averagely (Mean:3) were neutral about the fact that $t$ they had ability to automatically give feedback on their learning easily and practice more outside of the classroom environment.

It shows that the UPSA may neglect some aspects of the TEL standard to fully integrate the students' dimension and component into its system. This study's result is therefore in contradiction with the study made by (Pechenkina and Aeschliman 2017, Sivakumar and Robertson 2014) where they argue in support that the mode of TEL environment highly emulates classroom environment and is best in delivering remote laboratory experience and uses collaborative methods to achieve learning outcomes by facilitating inter-student communication.

\subsection{To ascertain the challenges of technology enabled-learning environment at UPSA}

The analysis indicated that for TELECRUIHAMS mean (3.70) SD (1.114) and UNEBOO mean (3.60) SD (.841) staffs agreed with those challenges whereby for UPSASREEUTTPA mean (3.45) SD (.932), ULDCE (3.35) SD (.975), FGIPALD mean (3.15) SD (.975) and UFOCSIPMY mean (2.63) SD (.979), staffs were neutral. Relatively, the average mean (3.3133) along with SD (0.9693) confirm the opinions of the last four variable stated previously. 
It is clearly justifiable from the analysis that the respondents were neutral regarding the challenges of TEL even though some of them agreed. Lucas (2017), Quinsee and Bullimore (2011) argue in support that major threats have been identified because it has been not really heralding the implementation of the new technology enable learning environment. Therefore, the finding confirms the study made by Lucas (2017) where he stated Lack of the Resources Required and University Administration as major factors of TEL.

In fact, he supports that TEL is costly and necessitate a huge investment from the university which some time deals with faculty resistance and resources' allocation in addition to an effective vision and leadership forcing the university to embrace bureaucracy in their operations. Furthermore, in regard of the conceptual framework. In fact, according to the average mean of objective one (1) and from Figure 6, anytime the long-term policy and planning is reviewed or evolved, the challenges also increase as well. Therefore, from the conceptual framework (see Chapter two, section 2.8), the influence that a university is subjected can enhance or derail it strategic initiative and therefore, having a negative influence on students (Price et al., 2016).

\section{Conclusion}

The study was to explore the quality of teaching, learning, and management strategies that were of importance and critically needed in higher education in Ghana through the assessment of management in the use of the appropriate technologies, processes, and resources with UPSA as case study. A review of the literature showed gaps in the use of technology which informed the objectives of the study. Hence the study focused on management practices and aptitude toward their readiness in a technology-enabled learning environment and explored students' perspectives when assessing technology-enabled learning.

The conceptual framework outlined in chapter two presented the areas an academic institution should emphasize on and the results indicated that most respondents were knowledgeable enough based on respondents of the survey. Regards to the TEL environment's benefits, the status of TEL was not good since the university has not been able to provide the standard requirement such an academic environment requires. The study also showed that the university should closely look at the aspects of faculty governance that may inhibit or hinder the ability of academic leadership to foster and promote the mode of TEL such RIL, RLR and IHL necessary for an effective emulator and collaborative environment.

In addition, it shows how the influence a university is subjected to can enhance or derail its strategic initiative and negatively influence the students, suggesting that long-term policy and strategic planning and leadership are closely related to the challenges of TEL.

We recommended that UPSA should exemplify the feasibility of designing an e-education system for strong remote student interaction with faculty in onsite lectures.

(1) UPSA should implement a pedagogical and instructional level knowledge mostly in need of active, collaborative remote online laboratory instruction. (2) UPSA should incorporate effective remote site facilitation to mimic the face-to-face interaction taking place in onsite laboratories. (3) UPSA should improve upon faculty governance to promote progress and intensify academic leadership which will drive the changes effectively. (4) 
UPSA should implement a risk management strategy to effectively monitor the TEL environment challenges that may arise and to make important improvements.

\section{Declarations}

\section{Source of Funding}

This research did not receive any specific grant from funding agencies in the public, commercial, or not-for-profit sectors.

\section{Competing Interests Statement}

The authors declare no competing financial, professional and personal interests.

\section{Ethical Approval}

Not Applicable

\section{Consent to participate}

Not Applicable

\section{Consent for publication}

We declare that we consented for the publication of this research work.

\section{Availability of data and material}

Authors are willing to share data and material according to the relevant needs.

\section{References}

Aderi, M., Noh, C., Andayani, S., and Yusuf, M. (2018) Collaborative Learning Technique within Higher Learning Education Students. 2367-2375.

Akers, R. (2017) Social Learning and Social Structure: A General Theory of Crime and Deviance [online] 1st Editio. New York: Routledge. available from <https://www.taylorfrancis.com/books/9781315129587>.

Al, B.Y. and Dunagan, A.N.A. (2017) College Transformed : Five Institutions Leading the Charge in Innovation. Amy K.,S. and Andrea, M. (2012) 'Learner Engagement for Success in the Innovation Age: Portfolio, Strengths-Based, and Collaborative Learning Strategies'. Cutting-Edge Tech. in Higher Education 6, 17-55.

Anthony F., C. and Anne-Christin, T. (2013) ‘Assessment and Recognition of Open Learning’. Advances in Digital Education and Lifelong Learning [online] 1, 85-118.

Capital Wave (2017) Technology Enabled Learning [online] available from <https://www.capitalwave.com>.

Demirkan, H. and Spohrer, J. (2015) 'T-Shaped Innovators: Identifying the Right Talent to Support Service Innovation'. Research-Technology Management [online] 58 (5), 12-15. available from <https://doi.org/10.5437/08956308X5805007>. 
DIGGS, C.K. (2014) Understanding teacher perspectives about instructional technology from an ecology of resources framework. University of Missouri-Columbia.

Edelson, D.C., Gordin, D.N., and Pea, R.D. (1999) 'Addressing the Challenges of Inquiry-Based Learning Through Technology and Curriculum Design'. Journal of the Learning Sciences [online] 8 (3-4), 391-450.

ELearning industry (2019) 5-Technology-Enabled-Learning-Trends-2017.

Emergingedtech (2019) 8 Exciting Technology-Enhanced Teaching and Learning Approaches That Teachers Are Embracing in 2014.

Felix A., K. (2013) 'Technology and the Changing Nature of Narratives in Language Learning and Teaching, in Laura A'. Cutting-Edge Technologies in Higher Education, [online] 6, 95-119.

Fisher, C. (2010) Researching and Writing a Dissertation. 3rd edn. Edinburgh Gate: Pearson Education Limited. Gillies, R.M. and Gillies, R.M. (2016) Cooperative Learning : Review of Research and Practice. 41 (3).

Gorghiu, G., Drăghicescu, L.M., Cristea, S., Petrescu, A.-M., and Gorghiu, L.M. (2015) 'Problem-Based Learning - An Efficient Learning Strategy in the Science Lessons Context'. Procedia - Social and Behavioral Sciences [online] 191, 1865-1870.

Hall, R. (2011) 'Towards a Resilient Strategy for Technology-Enhanced Learning'. Campus-Wide Information Systems 28 (4), 234-249.

Kwame, J., Edumadze, E., and Owusu, A.A. (2013) 'Use of Information and Communication Technology for Teaching and Learning in Ghanaian Universities: Case of University of Cape Coast'. International Journal of Computing Academic Research [online] 2 (6), 2305-9184.

Lucas, H.C. (2017) 'Technology and the Failure of the University'. Communications of the ACM 61 (1), 38-41. Martín-Gutiérrez, J., Fabiani, P., Benesova, W., Meneses, M.D., and Mora, C.E. (2015) 'Augmented Reality to Promote Collaborative and Autonomous Learning in Higher Education'. Comp. in Human Behavior 51, 752-761.

Nooraie, M. (2008) 'Decision Magnitude of Impact and Strategic Decision-making Process Output'. Management Decision [online] 46 (4), 640-655.

Novack, M. \& Goldin-Meadow, S.E.P.R. (2015) 'Learning from Gesture: How Our Hands Change Our Minds'. Educational Psychology Review [online] 27 (3), 405-412.

Pechenkina, E. and Aeschliman, C. (2017) What Do Students Want? Making Sense of Student Preferences in Technology-Enhanced Learning. 8 (1), 26-39.

'Pedagogy and Technology-Enhanced Learning, in Matt Bower' (2017) Design of Tech.-Enh. Lear. 35-63.

Pedaste, M., Mäeots, M., Siiman, L.A., Jong, T. De, Zacharia, Z.C., and Tsourlidaki, E. (2015) 'Phases of Inquiry-Based Learning: Definitions and the Inquiry Cycle'. Educational Research Review [online] 14, 47-61. available from 〈http://dx.doi.org/10.1016/j.edurev.2015.02.003〉. 
Peng, H., Ma, S., and Spector, J.M. (2019) 'Personalized Adaptive Learning: An Emerging Pedagogical Approach Enabled by a Smart Learning Environment'. in Chang, M., Popescu, E., Kinshuk, Chen, N.-S., Jemni, M., Huang, R., Spector, J Michael, and Sampson, D.G. (eds.) Foundations and Trends in Smart Learning. held 2019 at Singapore. Springer Singapore, 171-176.

Peter, H. and Esther, L. (2013) Increasing Learner Engagement of Learning Technologies and Science TPACK Through Representational Challenges, in Charles Wankel, Patrick Blessinger (Ed.) Increasing Student Engagement and Retention in e-Learning Environments: Web 2.0 and Blended Learning . [online] 6, 83-112. available from <https://emeraldinsight.com/doi/pdfplus/10.1108/S2044-9968\%282013\%29000006G006>.

Price, L., et al., (2016) Modeling an institutional approach to developing technology enabled learning: closing the gap between research and practice linda price, Diogo Casanova and Suzan Orwell. 1-10.

Quinsee, S. and Bullimore, A. (2011) 'Creating the Strategic Learning Environment at City University London'. Campus-Wide Information Systems 28 (4), 275-288.

Robin, B.R. (2016) 'The Power of Digital Storytelling to Support Teaching and Learning'. Digital Education Review [online] (30), 17-29. available from 〈http://greav.ub.edu/der/>.

Saunders, M., Lewis, P., and Thornhill, A. (2009) Research Methods for Business Students. 5th edn. Edinburgh Gate: Pearson Education Limited.

Shawn, M.B. (2015) 'Digital Technologies and Diverse Learning in Teacher Education: Reassembling the Social Perspective'. Advances in Research on Teaching [online] 25, 5-23.

Sivakumar, S.C. and Robertson, W. (2014) 'Developing an Integrated Web Engine for Online Internetworking Education: A Case Study’. Internet Research 14 (2), 175-192

Tech.ed (2019) Learning [online] available from <https://tech.ed.gov/netp/learning/> [8 August 2019]

University of Professional Studies (2018) Students’ Hanbook. Accra, 2

UPSA (2018) 'UPSA ANNUAL Report 2018'. The University of Professional Studies, ACCRA (UPSA) [online] available from <http://www.mediafire.com/file/ntq981ejr8i578f/UPSA_2018_ANNUAL_REPORT.pdf/file>

Yew, E.H.J. and Goh, K. (2016) 'Problem-Based Learning: An Overview of Its Process and Impact on Learning'. Health Professions Education [online] 2 (2), 75-79.

yourtrainingedge (2019) Whats-in-Your-Technology-Enabled-Learning-Toolbox [online] available from <https://www.yourtrainingedge.com> [10 February 2019]

Zbyněk, F. and Rohlíková, L. (2018) 'Preservice Teachers and Active Learning in Technology-Enhanced Learning: The Case of the University of West Bohemia in the Czech Republic'. Active Learning Strategies in Higher Education [online] 211-245. 